\title{
Manifestações Reumáticas associadas ao Vírus Linfotrópico Humano de Células T do Tipo I (HTLV-I) ${ }^{*}$
}

\section{Rheumatic Manifestations associated with the Human T-Cell Lymphotropic Virus Type I (HTLV-I)}

\author{
Boris A. Cruz ${ }^{(1)}$, Bernadete Catalan-Soares ${ }^{(2)}$, Fernando Proietti ${ }^{(3)}$
}

\begin{abstract}
RESUMO
O vírus linfotrópico humano de células T tipo I (HTLV-I) é reconhecido como agente etiológico da leucemia de células $\mathrm{T}$ do adulto. O HTLV-I é também relacionado a uma mielopatia crônica, que inclui agressão inflamatória (auto) imune-mediada em sua patogênese. Outras síndromes auto-imunes, dentre as quais artrite reumatóide e síndrome de Sjögren são descritas em pacientes infectados. Nestes pacientes, estas condições clínicas parecem ser o resultado da interação entre o vírus como fator do ambiente e susceptibilidade do hospedeiro, levando ao funcionamento aberrante de mecanismos imuno-moduladores, proliferação celular e inflamação. O estudo dos aspectos clínicos e imunológicos das manifestações reumáticas associadas ao HTLV-I pode contribuir para o melhor entendimento das doenças auto-imunes.
\end{abstract}

Palavras-chave: HTLV-I, manifestações reumáticas, artrite reumatóide, síndrome de Sjögren, fibromialgia.

\section{INTRODUÇÃO}

Doenças reumáticas auto-imunes são síndromes clínicas em que o dano tissular acontece a partir de uma resposta do sistema imunológico a auto-antígenos ${ }^{(1)}$. Genericamente, tais doenças podem ser entendidas como o resultado da interação entre predisposição genética e fatores ambientais ${ }^{(1,2)}$. Em diferentes estudos, um número crescente de agentes infecciosos, incluindo bactérias e vírus, vêm sendo descritos como fatores do ambiente capazes de deflagrar condições auto-imunes.

\begin{abstract}
The Human T-Cell Lymphotropic Virus Type I is known as the etiologic agent of Adult T-Cell Leukemia. The HTLV-I is also related to a chronic myelopathy, which includes (auto) immunemediated inflammatory injury in its pathogenesis. Other autoimmune syndromes such as Rheumatoid Arthritis and Sjögren's Syndrome are reported in infected patients. In those patients, these clinical conditions seem to be the result of the interaction between the virus as an environmental agent and host susceptibility, leading to an aberrant functioning of immunomodulatory mechanisms, cellular proliferation and inflammation. The study of clinical and immunological aspects of the HTLV-I-associated rheumatic manifestations may contribute to the better understanding of the auto-immune diseases.
\end{abstract}

Keywords: HTLV-I, rheumatic manifestations, rheumatoid arthritis, Sjögren's syndrome, fibromyalgia.

Particularmente determinados patógenos linfotrópicos como $\mathrm{o}$ vírus da imunodeficiência humana e o vírus da hepatite $\mathrm{C}$, por meio de mimetismo molecular e/ou imunomodulação, podem induzir reatividade cruzada contra auto-antígenos e funcionamento aberrante de linfócitos B e T, causando inflamação e expressão clínica da doença ${ }^{(1-4)}$.

$\mathrm{O}$ vírus linfotrópico humano de células tipo I (HTLV-I), classificado como membro da família oncoretroviridae, foi inicialmente descrito como agente causador da leucemia de células T do adulto (ATLL) ${ }^{(5,6,8)}$. O HTLV-I é também impli-

* Trabalho realizado na Universidade Federal de Minas Gerais (UFMG), Belo Horizonte, MG, Brasil, com a participação do Grupo Interdisciplinar de Pesquisa em HTLV-I/II (GIPH). Recebido em 24/10/2004. Aprovado, após revisão, em 25/1 1/2004.

1. Especialista em Reumatologia. Serviço de Reumatologia do BIOCOR Instituto, Nova Lima, MG, Brasil. Departamento de Medicina Preventiva da Faculdade de Medicina da UFMG.

2. Mestre em Medicina. Departamento de Medicina Preventiva da Faculdade de Medicina da UFMG. Hemocentro de Belo Horizonte/Fundação Hemominas, Belo Horizonte, MG, Brasil.

3. Doutor em Ciências da Saúde. Departamento de Medicina Preventiva da Faculdade de Medicina da UFMG.

Endereço para correspondência: Dr. Boris Afonso Cruz. Rua Fernandes Tourinho, 999, sala 107, CEP 30.380-780, Belo Horizonte, MG, Brasil. Tel. (31) 3284-7766; fax (31) 3225-57 12; e-mail: boriscruz@terra.com.br 
cado como agente etiológico de uma forma de mielopatia crônica progressiva, denominada mielopatia associada ao HTLV-I/paraparesia espástica tropical (HAM/TSP) $)^{(7,8)}$. Além destas síndromes, uma série de outras condições inflamatórias vêm sendo associadas ao HTLV-I, dentre as quais doenças reumáticas como artrite reumatóide e síndrome de Sjögren. O objetivo desta revisão é discutir os aspectos clínico-epidemiológicos e imunopatogênicos das manifestações reumáticas descritas em pacientes infectados pelo HTLV-I.

\section{ASPECTOS EPIDEMIOLÓGICOS E CLÍNICOS DA INFECÇÃO PELO HTLV-I}

A partir de sua descrição em 1980, estudos sero-epidemiológicos mostraram alta prevalência (>10\%) de HTLV-I em adultos saudáveis no sudoeste do Japão e taxas moderadas no Caribe e África ocidental ${ }^{(8)}$. Estudos na América Latina mostram números expressivos em praticamente todos os países. No Brasil, a prevalência média relatada em doadores de sangue é de 0,46\%, com taxas variáveis nas diferentes regiões do país. Esta taxa é 20 a 100 vezes maior que nos Estados Unidos ou na Europa. Tais dados, associados à extensão territorial do país e a sua população, sugerem que o Brasil tem cerca de 2,5 milhões de indivíduos sero-positivos para HTLV-I/II - possivelmente o maior número absoluto de indivíduos infectados no mundo ${ }^{(9,10)}$.

A transmissão do vírus ocorre por contato sexual, inoculação parenteral como doação de sangue não-triado ou compartilhamento de agulhas por usuários de drogas injetáveis e verticalmente (de mãe para filho), predominantemente por meio do aleitamento materno. Na infância, a soropositividade para HTLV-I é muito baixa e aumenta a partir da adolescência e início da idade adulta, sendo este aumento mais acentuado em mulheres que em homens ${ }^{(8,9)}$.

O diagnóstico da infecção se faz a partir de dois tipos de testes: a) testes sorológicos de triagem, como aglutinação de partículas de látex ou ELISA (Enzyme linked immunosorbent assay) que não diferenciam as infecções entre os vírus do tipo I e do tipo II e b) testes sorológicos com maior acurácia como o Westernblot ou Imunoblot, que são utilizados como testes confirmatórios. Estes testes são capazes de identificar separadamente os dois tipos de HTLV, a partir da análise de diferentes antígenos virais. O teste de reação em cadeia de polimerase (PCR) é mais sensível e específico que os métodos anteriores. Apresenta ainda a vantagem de não ser dependente da presença de anticorpos, permitindo diagnósticos mais precoces a partir de sangue ou qualquer outro tecido corporal. A sua utilização, no entanto, é ainda restrita a pesquisas científicas, em razão de seu maior custo ${ }^{(8-10)}$.
Até 5\% dos indivíduos infectados pelo HTLV-I evoluem com HAM/TSP e cerca de 1\% desenvolvem ATLL. Estas duas doenças têm patogenias distintas e raramente coexistem em um mesmo paciente. Uma série de características do vírus e do hospedeiro como cepas diferentes, carga viral e polimorfismo de haplótipos HLA vêm sendo estudados como fatores determinantes da evolução da infecção, mas a contribuição relativa destes fatores na patogênese de ATLL e HAM/TSP não está estabelecida ${ }^{(8-11)}$.

O HTLV-II foi inicialmente isolado de dois pacientes com uma forma atípica de leucemia de células pilosas, mas esta associação não foi confirmada posteriormente. Existem raros casos descritos de doença neurológica em pacientes infectados. Alguns estudos sugerem maior predisposição a infecções bacterianas nestes indivíduos, mas até o momento não existem evidências definitivas da associação entre HTLV-II e síndromes clínicas específicas ${ }^{(10,11)}$.

\section{O HTLV-I E DOENÇAS REUMÁTICAS}

Em uma série de estudos, é descrita a associação entre HTLV-I e artropatia inflamatória crônica. O primeiro relato da associação entre HTLV-I e artrite ocorreu em uma mulher de 79 anos com ATLL ${ }^{(12)}$. Seguiu-se a descrição de um grupo de pacientes infectados por HTLV-I com artropatia crônica caracterizada por proliferação sinovial com importante destruição óssea e cartilaginosa, denominada a princípio como artropatia associada ao HTLV-I ${ }^{(13)}$. Novos estudos demonstraram, no entanto, que tal condição é clínica e histologicamente indistinta da artrite reumatóide ${ }^{(14,15)}$.

Estudos epidemiológicos descrevem a associação entre HTLV-I e artrite reumatóide. Em um estudo observacional transversal realizado na ilha de Tsushima, onde 26,7\% dos habitantes são infectados pelo HTLV-I, Motokawa et al. demonstraram que a prevalência de artrite reumatóide era significativamente maior em pacientes sero-positivos em comparação à população sero-negativa para HTLV-I (0,56\% vs $0,31 \% ; \mathrm{p}<0,05)^{(16)}$. Em um estudo caso-controle, Eguchi et al. estimaram o Odds ratio para infecção por HTLV-I em pacientes com artrite reumatóide em 2,8 (95\% CI 1,8-4.6) ${ }^{(17)}$. Em outro estudo realizado também em área endêmica na África do Sul, entretanto, não se verificaram sinais de infecção pelo HTLV-I em 110 negros africanos com diagnóstico de artrite reumatóide ${ }^{(18)}$.

No único estudo realizado no Brasil sobre a prevalência de infecção pelo HTLV-I em pacientes com doenças reumáticas, Lonzetti et al. observaram sorologia positiva para HTLV-I/II em 5/69 pacientes com artrite reumatóide $(7,0 \%)$, enquanto a positividade observada no grupo con- 
trole de doadores de sangue foi de 1,3\%. Neste mesmo estudo, em um grupo de 33 pacientes com lúpus eritematoso sistêmico, não foi encontrado nenhum caso de sorologia positiva para HTLV-I/II ${ }^{(19)}$.

Em um estudo prospectivo, Murphy et al. relataram uma maior incidência de "artrite" em indivíduos infectados pelo HTLV-I, em comparação com doadores de sangue com sorologia negativa, após seguimento médio de 4,3 anos (risco relativo $=2,84$; IC95\% 1,53-5,33). Foi utilizado como instrumento de coleta de dados, entretanto, um questionário que não permitiu diferenciar o tipo de acometimento articular ${ }^{(20)}$.

A síndrome de Sjögren é uma doença auto-imune caracterizada pela infiltração por linfócitos $\mathrm{T}$ das glândulas salivares e lacrimais, causando a destruição de sua estrutura ductal e secura de mucosas oral e conjuntival. Eventualmente podem ocorrer outros sintomas inflamatórios sistêmicos como pneumonite, vasculite e comprometimento do sistema nervoso central ${ }^{(21)}$. Vários mecanismos patogênicos foram propostos, incluindo determinantes genéticos, fatores hormonais e infecções virais como hepatite C e outros retrovírus, mas não existem evidências de uma etiologia definitiva ${ }^{(22-27)}$. A associação entre HTLV-I e síndrome de Sjögren foi descrita por Vernant et al. em 1988, a partir de cinco pacientes das Índias Ocidentais com HAM/TSP e alveolite linfocítica, que preenchiam critérios diagnósticos para a exocrinopatia ${ }^{(28)}$. Mariette et al. ${ }^{(29)} \mathrm{e}$ Vogetseder et al. ${ }^{(30)}$ demonstraram uma alta prevalência de anticorpos contra HTLV-I em pacientes com síndrome de Sjögren. Autores japoneses verificaram o mesmo em áreas endêmicas ${ }^{(31)}$ de seu país, sendo que em uma série foram encontrados anticorpos anti-HTLV-I da classe IgA preferencialmente na saliva de indivíduos infectados com síndrome de Sjögren, em comparação aos pacientes com outras doenças relacionadas ao HTLV-I como HAM/TSP ${ }^{(32)}$.

As características clínicas e laboratoriais dos pacientes com síndrome de Sjögren e infecção pelo HTLV-I não parecem diferir das dos pacientes sem a infecção viral. Em um estudo japonês, porém, o grau de infiltração de células mononucleares nas glândulas salivares acessórias foi maior em pacientes com síndrome de Sjögren e infecção pelo HTLV-I em comparação aos pacientes com a mesma enfermidade reumática e sorologia negativa para HTLV-I/II ${ }^{(33,34)}$.

Em estudos de relatos de caso e séries de casos, outras condições reumáticas e/ou auto-imunes são descritas em associação com HTLV-I, como uveíte ${ }^{(35-37)}$, pneumonite intersticial $^{(37-38)}$, psoríase $^{(40)}$, polimiosite ${ }^{(41)}$, doença mista do tecido conjuntivo $^{(42)}$, doença de Behçet ${ }^{(43,44)}$ e outras formas de vasculite $^{(45,46)}$, mas não existem dados definitivos sobre uma relação causal entre a infecção viral e estas doenças. (Tabela 1).
TABELA 1

MANifESTAÇÕES REUMÁTICAS E/OU AUTO-IMUNES DESCRITAS EM PACIENTES INFECTADOS PELO HTLV-I

\begin{tabular}{lc}
\hline Manifestações reumáticas e/ou auto-imunes & Referências \\
\hline AAH*/artrite reumatóide & $12-20$ \\
síndrome de Sjögren & $28-34$ \\
Polimiosite & 41 \\
Uveíte & $35-37$ \\
Pneumonite intersticial & 37,38 \\
Doença mista do tecido conjuntivo & 42 \\
Doença de Behçet & 43,44 \\
\hline Outras vasculites & 45,46 \\
\hline
\end{tabular}

*Artropatia associada ao HTLV-I: a AAH foi inicialmente descrita como uma nova entidade clínica, mas trabalhos subseqüentes mostraram que se trata de uma doença clínica e histologicamente indistinta da artrite reumatóide

\section{FIBROMIALGIA E HTLV-I}

A fibromialgia é definida como uma síndrome dolorosa crônica não-inflamatória, caracterizada pela presença de dor musculoesquelética difusa e sensibilidade exacerbada à palpação de determinados sítios dolorosos. Estimativas acerca da prevalência variam de $2 \%$ na população geral a até $20 \%$ na prática clínica reumatológica, pelo que a fibromialgia é considerada a patologia reumática mais freqüente. Sua prevalência aumenta com a idade, sendo maior nas mulheres, existindo também associação com depressão ${ }^{(47-49)}$.

Diferentes teorias têm sido propostas sobre a patogênese desta síndrome, mas não existem dados conclusivos. A literatura descreve, como potenciais fatores desencadeantes, condições como trauma, estresse emocional agudo ou crônico e situações de imuno-estimulação, como pode ocorrer em uma série de doenças auto-imunes e determinadas infecções (p.ex., parvovírus e doença de Lyme) ${ }^{(47-49)}$.

Alguns estudos demonstraram maior prevalência de fibromialgia em grupos de indivíduos com determinadas infecções virais crônicas, notadamente infecção pelo vírus da imunodeficiência humana (HIV) ${ }^{(50,51)}$ e hepatite $\mathrm{C}^{(52,53)}$. Ambos são também vírus linfotrópicos e sabidamente associados a alterações de mecanismos imunorreguladores semelhantes aos descritos como responsáveis pelo desenvolvimento de HAM/TSP e artropatia em indivíduos infectados pelo HTLV-I ${ }^{(3,4,54)}$. Não existem estudos publicados sobre a associação entre fibromialgia e infecção pelo HTLV-I.

Alguns autores verificaram dor muscular e pontos sensíveis característicos de fibromialgia em pacientes com HAM/TSP (Cartier e Gotuzzo; comunicação pessoal). Na coorte do Grupo Interdisciplinar de Pesquisa em HTLV-I/II 
(GIPH), que inclui candidatos à doação de sangue em quem se verificou sorologia positiva para HTLV-I/II e pacientes com HAM/TSP, observações preliminares sugerem uma maior prevalência de fibromialgia em indivíduos infectados. Em um estudo piloto, realizado por um dos autores (BAC), que incluiu apenas indivíduos com sorologia positiva para HTLV-I $(n=32)$, a prevalência de fibromialgia foi 19\% (dados não publicados). Em outra avaliação transversal com mascaramento da sorologia dos sujeitos da pesquisa, que incluiu indivíduos com sorologia positiva $(n=17)$, indeterminada $(n=7)$ e negativa $(n=5)$ para HTLV-I/II, a prevalência de fibromialgia foi $29 \%, 0 \%$ e $0 \%$, respectivamente (dados não publicados). Está em andamento nesta coorte um estudo com maior casuística, para melhor avaliar a prevalência de fibromialgia em indivíduos infectados pelo HTLV-I.

\section{PATOGÊNESE DAS MANIFESTAÇÕES REUMÁTICAS ASSOCIADAS AO HTLV-I}

Vários estudos têm investigado os mecanismos fisiopatológicos das doenças associadas ao HTLV-I, mas os resultados são ainda inconclusivos. No entanto, alguns autores sugerem que alterações de mecanismos de imunorregulação seriam os responsáveis pelo desenvolvimento dessas condições clínicas ${ }^{(55-57)}$. Indivíduos infectados têm suas funções celulares moduladas pelo HTLV-I. Quando da infecção pelo HTLV-I, a partir da transcrição reversa, o DNA pró-viral integra-se ao genoma das células do hospedeiro. Sua porção $\mathrm{pX}$ pode codificar várias proteínas, dentre as quais uma fosfoproteína de $40 \mathrm{KD}$ denominada p40 Tax. A partir de sua interação com fatores celulares e genoma pró-viral, a p40 Tax regula não só a replicação viral, mas também a expressão celular de vários genes, particularmente aqueles envolvidos em inflamação e proliferação celular, como interleucina IL-1, IL-2, subunidade alfa do receptor de IL-2 (IL-2R $\alpha$ ), fator estimulador de crescimento de colônias granulócito-macrófago (GM-CSF), fator de necrose tumoral $\alpha$ (TNF- $\alpha$ ), moléculas de adesão como ICAM-1 e oncogenes como jun, fos, rel, myc e ets ${ }^{(58,59)}$. Os produtos da ativação destes genes seriam os responsáveis pela migração de linfócitos infectados para o tecido sinovial e sua ativação ${ }^{(59)}$. Existem evidências de produtos gênicos do HTLV-I não só em linfócitos $\mathrm{T}$ infectados, mas também em outras células da linhagem sinovial como macrófagos e fibroblastos $^{(60)}$. Células infectadas seriam capazes de produzir TNF$\alpha$ e a partir daí provocar a proliferação sinovial, formação de "pannus" e a destruição da cartilagem, com conseqüente erosão articular. Este processo já foi demonstrado em camundongos transgênicos para a env-pX do HTLV-I, que expressam $\mathrm{p} 40 \operatorname{Tax}^{(61,62)}$.

Em pacientes infectados pelo HTLV-I e síndrome de Sjögren, estudos sugerem que, a partir de penetração da barreira endotelial, células mononucleares infectadas podem alcançar o tecido glandular e causar um processo inflamatório com destruição da estrutura ductal por mecanismos semelhantes aos descritos para a artropatia associada ao HTLV-I ${ }^{(63,64)}$ (Figura 1).

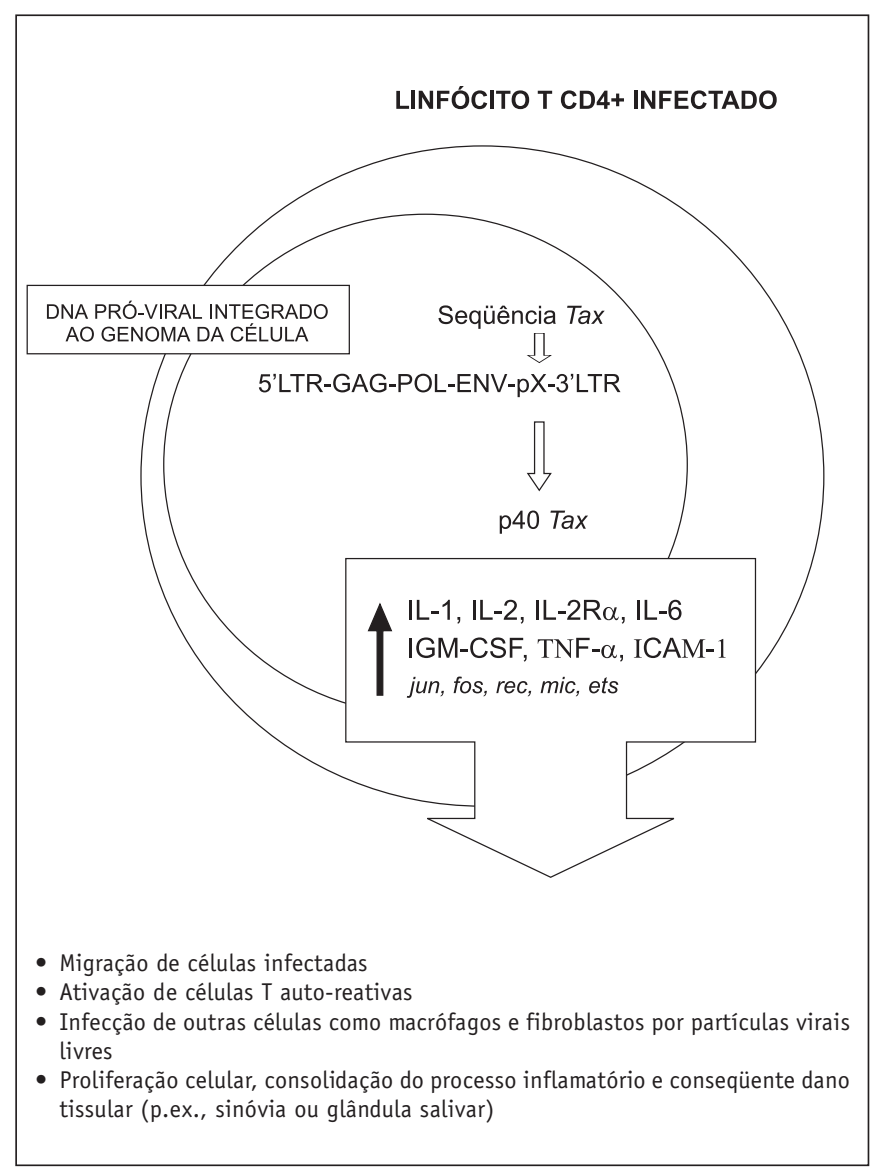

FIgURA 1 - Representação esquemática da patogênese de doenças reumáticas associadas ao HTLV-I: A partir da integração do DNA pró-viral ao genoma da célula infectada, a região pX codifica p40 Tax. Através de sua interação com fatores celulares, p40 Tax induz a expressão de genes envolvidos em inflamação/proliferação celular como: interleucina(IL)-1, IL-2, subunidade alfa do receptor de IL-2 (IL-2R $)$, IL-6, fator estimulador de crescimento de colônias granulócito-macrófago (GM-CSF), fator de necrose tumoral $\alpha$ (TNF- $\alpha$ ), moléculas de adesão como ICAM-1 e oncogenes como jun, fos rel, myc e ets. Os produtos destes genes causam a migração de linfócitos infectados, a ativação/proliferação de células T auto-reativas e conseqüente inflamação nos órgãos-alvo como a sinóvia e as glândulas salivares 


\section{O ESTADO "SOMENTE-TAX"}

Discute-se um possível papel para o gene HTLV-I Tax em pacientes com doenças reumáticas e sorologia negativa para o vírus, descritos na literatura inglesa como "tax-only state"(3,15,65). Em um estudo realizado nos Estados Unidos da América, Zucker-Franklin et al. avaliaram 102 pacientes com artrite reumatóide por intermédio de técnicas de PCR para o gene HTLV-I Tax e sorologia para p40 Tax. Em um paciente confirmou-se a infecção pelo HTLV-I por meio de sorologia positiva e a verificação de outras seqüências do DNA próviral, além de HTLV-I tax. Entre 101 pacientes com sorologia negativa para HTLV-I/II, 25 apresentaram seqüência de HTLVI Tax em células mononucleares e positividade na sorologia para p40 Tax - uma prevalência três vezes maior que em doadores de sangue sem artrite reumatóide ${ }^{(66)}$.

Mariette et al. detectaram gene HTLV-I tax, mas não outras seqüências do DNA pró-viral como gag, pol ou env em 2 de 9 pacientes com síndrome de Sjögren, com sorologia negativa para HTLV-I ${ }^{(67)}$. Um estudo japonês apresentou resultados semelhantes ${ }^{(68)}$. No entanto, um estudo britânico que utilizou técnicas de PCR para HTLV-I Tax em 49 biópsias de glândulas salivares - 26 pacientes com síndrome de Sjögren primária, 8 com síndrome de Sjögren secundária e 15 controles - não encontrou positividade para Tax em nenhuma das amostras ${ }^{(69)}$.

Existem três possíveis explicações para os resultados encontrados nestes estudos. Primeiramente, pode ser

\section{REFERÊNCIAS}

1. Davidson A, Diamond B: Autoimmune diseases. N Engl J Med 345 340-50, 2001.

2. Krause A, Kamrad T, Burmeister GR: Potencial infectious agents in the induction of arthritides. Curr Opin Rheumatol 8:203-9, 1996.

3. Cooke SP, Rigby SP, Griffiths DJ, Venables PJ: Viral studies in rheumatic disease. Ann Med Interne 149: 30-3, 1998

4. Perl A: Mechanisms of viral pathogenesis in rheumatic disease. Ann Rheum Dis 58: 454-61, 1999.

5. Uchiyama T, Yodoi J, Sagawa K, Takatsuki K, Uchino H: Adult Tcell leukemia: clinical and hematological features of 16 cases. Blood 50: 481-92, 1977.

6. Takatsuki K, Yamaguchi K, Kawano F, et al: Clinical diversity in adult T-cell leukemia-lymphoma. Cancer Res 45 (suppl): 4644S-5S, 1985.

7. Osame M, Usuku K, Izumo S, et al: HTLV-I associated myelopathy, a new disease entity. Lancet 1:1031-2, 1986.

8. Ifthikharuddin JJ, Rosenblatt JD: Human T-Cell Lymphotropic Virus Types I and II In: Mandell GL, Douglas JE, Dolin R. Mandell, Douglas and Bennett's principles and practice of infectious diseases, 5th ed. Philadelphia: Churchil Livingston, 2000. sugerido que os pacientes foram infectados por vírus defectivos e que a maior parte do genoma viral que não Tax foi perdida. A segunda explicação seria uma infecção pelo HTLV-I propriamente dito, mas persistência da sorologia negativa e falência em se detectar outras partes do genoma por homologia pobre ou fatores técnicos associados à PCR. A terceira possibilidade seria positividade das reações de PCR para Tax apenas por artefatos de contaminação ${ }^{(3)}$. Outros estudos são necessários para se definir a importância de Tax em pacientes com doenças reumáticas auto-imunes e sorologia negativa para HTLV-I.

Concluindo-se, em indivíduos geneticamente suscetíveis, auto-imunidade pode ser desencadeada por fatores relacionados ao ambiente, incluindo infecções virais crônicas. A partir das evidências descritas neste texto, entendese que o HTLV-I é potencialmente associado à artrite reumatóide e à síndrome de Sjögren. Outras doenças reumáticas, dentre as quais a fibromialgia, podem estar também relacionadas ao HTLV-I, mas outros estudos são necessários para melhor definição desta associação.

A investigação de aspectos clínicos e imunológicos das manifestações reumáticas associadas a infecções virais como HTLV-I pode fornecer informações valiosas para o melhor entendimento dos mecanismos patogênicos das doenças auto-imunes e subsidiar a implementação de estratégias preventivas no âmbito pessoal e coletivo.

9. Carneiro-Proietti ABF, Catalan-Soares B, Proietti FA: Human T cell lymphotropic viruses (HTLV-I/II) in South America: should it be a public health concern? J Biomed Sci 9:587-95, 2002.

10. Catalan-Soares B, Proietti FA, Carneiro-Proietti ABF: Os vírus linfotrópicos de células T humanos (HTLV) na última década (19902000). Aspectos epidemiológicos. Rev Bras Epidemiol 4:81-95, 2001.

11. Barmak K, Harhaj E, Grant C, Alefantis T, Wigdahl B: Human T cell leukemia vírus type I-induced disease: pathways to câncer and neurodegeneration. Virology 308:1-12, 2003.

12. Taniguchi A, Takenaka Y, Noda Y, et al: Adult T cell leukemia presenting with proliferative sinovitys (letter) Arthritis Rheum 31:1076-7, 1988.

13. Sato K, Maruyama I, Maruyama Y, et al: Arthritis in patients infected with human T lymphotropic virus type I: clinical and imunopathologic features. Arthritis Rheum 34: 714-21, 1991.

14. McCallun RM, Patel DD, Moore JO, Haynes BF: Arthritis syndromes associated with human $\mathrm{T}$ cell lymphotropic vírus type I infection. Med Clin North Am 81:261-76, 1997.

15. Nishioka K, Sumida T, Hasunuma T: Human T lymphotropic virus type $\mathrm{I}$ in arthropathy and autoimmune disorders. Arthritis Rheum 39: 1410-8, 1996. 
16. Motokawa S, Hasunuma T, Tajima K, et al: High prevalence of arthropathy in HTLV-1 carriers on a Japanese island. Ann Rheum Dis 55:193-5, 1996.

17. Eguchi K, Origuchi T, Takashima H, Iwata K, Katamine S, Nagataki S: High seroprevalence of anti-HTLV-1 antibody in Rheumatoid Arthritis. Arthritis Rheum 39: 463-6, 1996.

18. Sebastian D, Nayiager S, York DY, Mody GM: Lack of association of Human T-cell lymphotrophic virus type 1(HTLV-1) infection and rheumatoid arthritis in an endemic area. Clin Rheumatol 22:302, 2003.

19. Lonzetti LS, Menna-Barreto M, Schoeler M, Cichoski L, Antonini E, Staub H: High prevalence of HTLV-I infection among patients with rheumatoid arthritis living in Porto Alegre, Brazil. J Acquir Immune Defic Syndr Hum Retrovirol 20: p A54, 1999.

20. Murphy EL, Wang B, Sacher RA, et al: Respiratory and Urinary Tract Infections, Arthritis, and Asthma Associated with HTLV-I and HTLV-II Infection. Emerg Infec Dis 10:109-16, 2004.

21. Moutsopoulos HM, Chused TM, Mann DL, et al: Sjögren's syndrome (sicca syndrome): current issues. Ann Intern Med 92:212-26, 1980.

22. Papasteriades C, Skopouli FN, Drosos AA, Andonopoulos AP, Moutsopoulos HM: HLA-alloantigen associations in Greek patients with Sjögren's syndrome. J Autoimmunity 1:85-90, 1986.

23. Moriuchi J, Ichikawa I, Takaya M: Association between HLA and Sjögren's syndrome in Japanese patients. Arthritis Rheum 29: 1518-2, 1986.

24. Venables PJW, Ros MGR, Charles PJ, Melsom RD, Griffith PD, Maini RN: A seroepidemiological study of cytomegalovirus and Epstein-Barr virus in rheumatoid arthritis and sicca syndrome. Ann Rheum Dis 44:742-6, 1985.

25. Saito I, Shimuta M, Terauchi K, Tsubota K, Yodoi J, Miyasaka N: Increased expression of human thioredoxin/adult $\mathrm{T}$ cell leukemiaderived factor in Sjögren's syndrome. Arthritis Rheum 39:773-82, 1996.

26. Mariette X: Sjögren's syndrome and virus. Rev Med Intern 15:6016, 1994.

27. Haddad J, Deny P, Munz-Gotheil C, et al: Lymphocytic sialadenitis of Sjögren's syndrome associated with chronic hepatitis $\mathrm{C}$ virus liver disease. Lancet 339: 321-3, 1992.

28. Vernan JC, Buisson G, Magdeleine J, et al: T lymphocye alveolitis, tropical spastic paresis and Sjögren's syndrome (letter). Lancet 1:177, 1988.

29. Mariette X, Cherot P, Cazals D, Brocheriou C, Brouet JC, Agbalika F: Antibodies to HTLV-I in Sjögren's syndrome. Lancet 345:71, 1995.

30. Vogetseder W: Antibodies to HTLV-I in Sjögren's syndrome. Lancet 345:72, 1995.

31. Eguchi K, Matsuoka N, Ida H, et al: Primary Sjögren's syndrome with antibodies to HTLV-I: clinical and laboratory features. Ann Rheum Dis 51:769-76, 1992.

32. Terada K, Katamine S, Eguchi K, et al: Prevalence of serum and salivary antibodies to HTLV-I in Sjögren's syndrome. Lancet 344:1116-9, 1994.

33. Ohyama $\mathrm{Y}$, Nakamura S, Hara $\mathrm{H}$, et al: Accumulation of human $\mathrm{T}$ lymphotric vírus type I-associated Sjögren's Syndrome. Arthritis Rheum 41:1972-8, 1998.

34. Nakamura H, Kawakami A, Tominaga M, et al: Relationship between Sjögren's syndrome and human T-lymphotropic virus type I infection: follow-up study of 83 patients. J Lab Clin Med 135: 139-44, 2000 .
35. Mochizuki M, Watanabe T, Yamaguchi K, et al: HTLV-I uveitis: a distinct clinical entity caused by HTLV-I. Jpn J Câncer Res 83: 236-9, 1992.

36. Mochizuki M, Watanabe $\mathrm{T}$, Yamaguchi $\mathrm{K}$, et al: Uveitis associated with human T-cell lymphotropic virus type I. Am J Ophthalmol 114:123-9, 1992.

37. Merle H, Cabre P, Olindo S, Merle S, Smadja D: Ocular lesions in 200 patients infected by the human T-cell lymphotropic virus type 1 in martinique (French West Indies). Am J Ophthalmol 134: 190$5,2002$.

38. Sugimoto M: Interstitial pneumonia in patients with human T-cell lymphotropic virus type-1 infection. Nihon Kyobu Shikkan Gakkai Zashi 31 Suppl: 36-41, 1993.

39. Kompoliti A, Gage B, Sharma L, Daniels JC: Human T-cell lymphotropic virus type 1-associated myelopathy, Sjögren syndrome, and lymphocytic pneumonitis. Arch Neurol 53: 940-2, 1996.

40. Watanabe A, Kawajiri M, Ikezoe K, et al: HTLV-1-associated myelopathy/tropical spastic paraparesis accompanied with psoriasis. J Neurol Sci. 221: 95-7, 2004.

41. Morgan OS, Rodgers-Johnson P, Mora C, Char G: HTLV-1 and polymyositis in Jamaica. Lancet 2:1184-7, 1989.

42. Bownes P, Davies KAA, Tosswill J, et al: Autoimmune disease and HTLV-I infection. Br J Rheumatol 30: 141-3, 1991.

43. Igakura T, Kawahigashi $Y$, Kanazawa $H$, Nakagawa M, Osame M: HTLV-I and Behçet's disease. J Rheumatol 20: 2175-6, 1993.

44. Kanazawa H, Ijichi S, Eiraku N, et al: Behçet's disease and Sjögren syndrome in a patient with HTLV-I-associated myelopathy. J Neurol Sci 119: 121-2, 1993

45. Vernant JC, Smadja D, Deforge-Lasseur C, et al: Vasculitis and neurologic manifestations related to HTLV-1. Presse Medicale 23: 1421-5, 1994.

46. Schwartz J, Gonzalez J, Rosenberg R, et al: Cutaneous T-cell lymphoma, tropical spastic paraparesis, cerebral vasculitis, and protein S deficiency in a patient with HTLV-I. Southern Med J 89: 9991000, 1996.

47. Bennet RM: The fibromyalgia syndrome. In: Rudy S, Harrys ED, Sledge CB: Kelley's Textbook of Rheumatology, 5th ed, Pennsylvania: WB Saunders, 1997.

48. Carvalho MAP, Rego RR: Fibromialgia. In: Moreira C, Carvalho MAP: Reumatologia: Diagnóstico e Tratamento. 2a ed. Belo Horizonte: Medsi, 2001.

49. Kurtze N, Svebak S: Fatigue and patterns of pain in fibromyalgia: correlations with anxiety, depression and co-morbidity in a female county sample. Brit J Med Psychol 74: 523-37, 2001.

50. Simms RW, Zerbini CA, Ferrante N, Anthony J, Felson DT, Craven DE: Fibromyalgia syndrome in patients infected with human immunodeficiency virus. The Boston City Hospital Clinical AIDS Team. Am J Med 92: 368-74, 1992.

51. Cuellar ML: Rheumatic manifestations of HIV-AIDS. Baillieres Best Pract Res Clin Rheumatol 14: 579-93, 2000.

52. Goulding C, O'Connell P, Murray FE: Prevalence of fibromyalgia, anxiety and depression in chronic hepatitis $\mathrm{C}$ virus infection: relationship to RT-PCR status and mode of acquisition. Eur J Gastroenterol Hepatol 13: 507-511, 2001.

53. Buskila D, Shnaider A, Neumann L, Zilberman D, Hilzenrat N, Sikuler E: Fibromyalgia in Hepatitis C Virus Infection: Another Infectious Disease Relationship. Arch Intern Med 157:2497-500, 1997. 
54. Mogensen TH, Paludan SR: Molecular pathways in virus-induced cytokine production. Microbiol Mol Biol Rev 65:131-50, 2001.

55. Jacobson S: Cellular Immune Responses to HTLV-I: Immunopathogenic Role in HTLV-I-Associated Neurologic Disease. J Acquir Immune Defic Syndr Hum Retrovirol 13 (suppl. 1): S100-S 1996.

56. Höllsberg P: Pathogenesis of chronic progressive myelopathy associated with human T-cell lymphotropic virus type I. Acta Neurol Scan 95 (suppl. 169): 86-93, 1997.

57. Höllsberg P: Mechanisms of T-cell activation by human T-cel lymphotropic virus type I. Microbiol Mol Biol Rev 63: 308-33, 1999.

58. Barmak K, Harhaj E, Grant C, Alefantis T, Wigdahl B: Human T cell leukemia vírus typo I-induced disease: pathways to cancer and neurodegeneration. Virology 308: 1-12, 2003.

59. Iwakura Y, Saijo S, Kioka Y, et al: Autoimmunity induction by human $\mathrm{T}$ cell leukemia virus type 1 in transgenic mice that develop chronic inflammatory arthropathy resembling rheumatoid arthritis in humans. J Immunol 155: 1588-98, 1995.

60. Kitajima I, Maruyama K, Sato K, et al: Detection of human T cell leukemia virus type I proviral DNA and gene expression in synovial cells in chronic inflammatory arthropathy. J Clin Invest 88: 1315-22, 1991.

61. Yin W, Hasunuma T, Kobata T, Sumida T, Nishioka K: Synovial hyperplasia in HTLV-I associated arthropathy isinduced by tumor necrosis factor-alpha produced by HTVL-I infected CD68+ cells. J Rheumatol 27:874-81, 2000.
62. Iwakura Y, Tosu M, Yoshida E, et al: Induction of inflammatory arthropathy resembling rheumatoid arthritis in mice transgenic for HTLV-I. Science 253:1026-9, 1991.

63. Ichinose K, Nakamura T, Kawakami A, et al: Increased adherence of T cells to human endothelial cells in patients with human T-cell lymphotropic virus type I-associated myelopathy. Arch Neurol 49: 74-6, 1992.

64. Furuya $\mathrm{T}$, Nakamura $\mathrm{T}$, Shirabe $\mathrm{S}$, et al: Heightened transmigrating activity of CD4-positive $\mathrm{T}$ cells through reconstituted basement membrane in patients with human T-lymphotropic virus type Iassociated myelopathy. Proc Assoc Am Physicians 109: 228-36, 1997.

65. Zucker-Franklin D: Non-HIV retroviral associations with rheumatic disease. Curr Rheumatol Rep 2:156-162, 2000.

66. Zucker-Franklin D, Pancake BA, Brown WH: Prevalence of HTLV-I Tax in a subset of patients with rheumatoid arthritis. Clin Exp Rheumatol 20:161-9, 2002.

67. Mariette X, Agbalika F, Daneial MT, et al: Detection of human T lymphotropic vírus type I tax gene in salivary gland epithelium from two patients with Sjögren Syndrome. Arthritis Rheum 36:1423-8, 1993.

68. Sumida T, Yohana F, Maeda T, et al: Expression of sequences homologous to HTLV-I tax gene in the labial salivary glands of Japanese patients with Sjögren Syndrome. Arthritis Rheum 37: 545-50, 1994.

69. Rigby SP, Cooke SP, Weerasinghe D, Venables PJW: Absence of HTLV-I tax in Sjögrens syndrome (letter). Arthritis Rheum 39: 1609-10, 1996. 